\title{
Effect of frozen storage on polyphenol content and antioxidant activity of haskap berries (Lonicera caerulea L.)
}

\author{
Rabie Khattab ${ }^{\mathrm{a}, \mathrm{b}}$, Giovana Bonat Celli ${ }^{\mathrm{b}}$, Amyl Ghanem ${ }^{\mathrm{b}}$ and Marianne Su-Ling Brooks ${ }^{\mathrm{b}, *}$ \\ ${ }^{\mathrm{a}}$ Food Science Department, Faculty of Agriculture (Saba Basha), Alexandria University, Alexandria, Egypt \\ ${ }^{\mathrm{b}}$ Department of Process Engineering \& Applied Science, Dalhousie University, Halifax, NS, Canada
}

Submitted 3 May 2015; accepted 15 July 2015

\begin{abstract}
.
BACKGROUND: Haskap berries (Lonicera caerulea L.) are processed into various products (e.g. juice, jam and chutneys). These fruits are rich in bioactive compounds, though losses can occur during frozen storage, affecting the nutritional content of the products.

OBJECTIVE: To investigate the effect of freezing storage temperature $\left(-18\right.$ and $\left.-32^{\circ} \mathrm{C}\right)$ and steam blanching prior to freezing on the the total phenolic content (TPC)/total reducing capacity (TRC), total anthocyanin content (TAC) and antioxidant potential of three Haskap berry varieties; Tundra (T), Berry Blue (BB) and Indigo Gem (IG).

METHODS: Berries were stored at -18 or $-32^{\circ} \mathrm{C}$ for six months, and analyzed monthly for TPC/TRC, TAC, and DPPH radical scavenging activity. Steam blanching prior to freezing was also evaluated.

RESULTS: Frozen storage at $-18^{\circ} \mathrm{C}$ for six months reduced the TPC/TRC by 37.08 to $47.16 \%$. TAC was also reduced, where the highest decrease was for BB (59.24\%) followed by IG (46.34\%), and DPPH scavenging activity decreased by 26.78 to $30.86 \%$. Blanching prior to freezing improved the retention of bioactive compounds but storage at $-32^{\circ} \mathrm{C}$ did not yield significant improvements.
\end{abstract}

CONCLUSIONS: Steam blanching prior to freezing followed by frozen storage at $-18^{\circ} \mathrm{C}$ is recommended for better retention of the bioactive components of haskap berries.

Keywords: Haskap berry, Lonicera caerulea, frozen storage, polyphenols, antioxidant activity

\section{Introduction}

The nutritional and health benefits of berries have recently received significant consideration owing to their high content of polyphenols and associated anti-inflammatory, antioxidant, antimutagenic, and neuroprotective effects [1, 2]. Lonicera caerulea L., commonly known as the Haskap berry, has been traditionally used in Asia for its medicinal properties [3]. It has been recently introduced to the North American market [4], with processed products such as Haskap juice now available. Haskap berries are known to contain the highest amount of polyphenols among berries and other fruits, resulting in a higher antioxidant activity [5-7]. Their total phenolic content (TPC) and total anthocyanin content (TAC) are up to $11.42 \mathrm{mg}$ gallic acid equivalents per $\mathrm{g}$ of fresh weight, and $13.00 \mathrm{mg}$ cyanidin-3-glucoside equivalents per $\mathrm{g}$ of fresh weight $(\mathrm{FW})$, respectively [8-10].

*Corresponding author: Marianne Su-Ling Brooks, Department of Process Engineering \& Applied Science, Dalhousie University, B3H 4R2 Halifax, NS, Canada. Tel.: +1 902494 6482; E-mail: Su-Ling.Brooks@ dal.ca. 
Freezing is an important method used to retain fruit quality during long-term storage and enable the year-round processing of seasonal fruit products. However, quality deterioration can occur during freezing and frozen storage [11]. A storage temperature of $-18^{\circ} \mathrm{C}$ is typically used to reduce the chemical and biological spoilage of foods and to extend their shelf life. However, freezing causes cell breakage, allowing enzymatic reactions to occur. Therefore, anthocyanins and other phenolic compounds can degrade during freezing and more extensively during thawing, due to their interaction with oxidative enzymes. Several pre-freezing treatments can be industrially applied to fruits and vegetables to retain their quality. Among these treatments, blanching can be used to inactivate enzymes that cause detrimental changes during frozen storage. Rickman et al. [12] reported that blanching could prevent the oxidative degradation of phenolic antioxidants during storage. However, as water-soluble phenols may be leached into water during blanching, steam blanching is preferred [13, 14].

The effects of freezing and frozen storage on the anthocyanin content and phenolic profile of different berries have been investigated [15-17]. Considerable anthocyanin and ascorbic acid losses were reported in strawberries stored frozen for several months $[18,19]$. Significant losses in TAC, TPC and antioxidant potential were also reported in frozen stored pomegranate juice [20] and cherry fruits [21]. Poiana et al. [22] concluded that freezing at $-18^{\circ} \mathrm{C}$ decreased the bioactive compounds in the strawberry, sweet cherry and sour cherry juices.

Several studies have shown the effects of storage of fruits and their extracts at standard freezing temperatures $\left(-18^{\circ} \mathrm{C}\right)$. For example Lohachoompol et al. [23] examined the effects of freezing and storage $\left(-20^{\circ} \mathrm{C}\right.$ for three months) on the anthocyanin content and antioxidant activity of blueberries (Vaccinium corymbosum $\mathrm{L}$ ) and found no significant decrease in anthocyanin level and antioxidant activity. In another study done by De Ancos et al. [24], ellagic acid, total phenolic, and vitamin $\mathrm{C}$ contents were quantified by HPLC in fresh, just frozen, and frozen stored $\left(-20^{\circ} \mathrm{C}\right.$ for one year) raspberry fruits. The results showed that after 12 months, there was no change in TPC, whereas significant decreases in ellagic acid and vitamin $\mathrm{C}$ were observed. On the other hand, there have been fewer studies examining the effect of temperatures lower than the standard freezing temperature on the content of bioactive compounds. In these studies, differences in the retention of bioactive compounds were observed, depending on the fruit and sample conditions. For example, the polyphenol contents of apple and orange extracts were found to be stable during frozen storage at $-18^{\circ} \mathrm{C}$ and $-70^{\circ} \mathrm{C}$ for 10 days, and there was no significant difference in the retention rates for polyphenols and ascorbic acid between the two temperatures [25]. Also, Mullen et al. [17] found that the antioxidant capacity of the fresh red raspberries fruit and the levels of vitamin $\mathrm{C}$ and phenolic compounds were not affected by freezing at $-30^{\circ} \mathrm{C}$.

Freezing berries for juice production is extremely important due to the short harvest period. Currently, Haskap berries are frozen at $-18^{\circ} \mathrm{C}$, within hours of harvest and stored until needed. The frozen berries are typically thawed at room temperature and the juice is collected. Despite the high initial bioactive content in Haskap berries, losses during frozen storage and subsequent thawing may be significant. There have been no studies in the literature on the effect of frozen storage on the phenolic profile and antioxidant potential of Haskap berries. Therefore, the present study was conducted to investigate the effect of different freezing conditions (storage temperatures of -18 and $-32^{\circ} \mathrm{C}$ and steam blanching prior to freezing) on the the total phenolic content (TPC)/total reducing capacity (TRC), total anthocyanin content (TAC) and antioxidant potential of three Haskap berry varieties grown in Nova Scotia, Canada.

\section{Materials and methods}

\subsection{Haskap berries}

Haskap berries (Lonicera caerulea L.) of three varieties; Tundra (T), Berry Blue (BB) and Indigo Gem (IG) $(10 \mathrm{~kg}$ each) were obtained from LaHave Natural Farms, Blockhouse, Nova Scotia, Canada. The fruits from each variety were divided to four parts (A-D). Part A was used for the direct extraction and analysis as fresh samples (control). Part $\mathrm{B}$ was steam-blanched and consequently stored at $-18^{\circ} \mathrm{C}$ in order to study the effect of blanching as a pre-freezing treatment, whereas Part $\mathrm{C}$ was stored directly at $-18^{\circ} \mathrm{C}$ without blanching. Part $\mathrm{D}$ was directly stored at $-32^{\circ} \mathrm{C}$ to investigate the effect of lower temperature frozen storage and compare it with the conventional frozen storage at $-18^{\circ} \mathrm{C}$ (Part C). 


\subsection{Chemicals and phenolic standards}

The chemicals used for this research were of analytical and HPLC grades and were procured from Sigma Aldrich (Oakville, Ontario, Canada) and Fisher Scientific (Ottawa, Ontario, Canada).

\subsection{Blanching}

Steam blanching was carried out in batches. Berries were spread on a stainless steel kitchen strainer that was held over boiling water. The fruits were then exposed to the hot steam typically at a temperature close to $100^{\circ} \mathrm{C}$ for 20 seconds. Blanched fruits were packed in polyethylene bags (300 g each), sealed and prepared for freezing and storage.

\subsection{Freezing}

Haskap berries were packed in polyethylene Ziploc bags ( $300 \mathrm{~g}$ each), frozen and stored at either $-18^{\circ} \mathrm{C}$ or $-32^{\circ} \mathrm{C}$ for six months. Samples were taken every month for analysis. Prior to extraction, the frozen fruits were allowed to completely thaw at room temperature $\left(25 \pm 2^{\circ} \mathrm{C}\right)$ for $12 \mathrm{~h}$.

\subsection{Extraction of phenolic compounds from Haskap berries}

Fresh and frozen stored samples were homogenously mixed using a household food processor (Black \& Decker, Applica Consumer Products, Inc., Miramar, FL, USA). The homogenized samples ( $\mathrm{g}$ each) were extracted three times with $8 \mathrm{~mL}$ acidified ( $0.1 \%$ formic acid) $80 \%$ aqueous methanol using an ultra-sound water bath (FS20D, Fisher Scientific, Pittsburgh, PA, USA) for $15 \mathrm{~min}$ at room temperature $\left(25 \pm 2^{\circ} \mathrm{C}\right)$ followed by centrifugation (Sorval RT1, Thermo Scientific, Marietta, OH, USA) at $4^{\circ} \mathrm{C}$ for $10 \mathrm{~min}(2939 \times \mathrm{g})$. The three supernatants were poured together and the volume was made up to $25 \mathrm{~mL}$ with the solvent. The extracts were filtered through a $0.45 \mu \mathrm{m}$ syringe filter and kept frozen until analysis.

\subsection{Total phenolic content (TPC)/Total reducing capacity (TRC)}

TPC/TRC was measured using the Folin-Ciocalteau assay as per Singleton et al. [26] with a few modifications. Extracts $(0.1 \mathrm{~mL}$ each) were diluted to $0.5 \mathrm{~mL}$ with distilled water, and $2.5 \mathrm{~mL}$ of $0.2 \mathrm{~N}$ Folin-Ciocalteau's reagent (diluted 1:10 with distilled water) was added. After $5 \mathrm{~min}, 2.0 \mathrm{~mL}$ of sodium carbonate solution (7.5\%) was added. Samples were incubated for 2 hours in the dark, and the absorbance was measured at $760 \mathrm{~nm}$ using the Genesys $10 \mathrm{~S}$ UV/Visible spectrophotometer (Thermo Scientific, Marietta, OH, USA). Gallic acid was used for the calibration curve $\left(R^{2}=0.99\right)$, and the results of quadruplicate analyses were expressed as milligrams of gallic acid equivalents (GAE) per gram of fresh weight (FW).

\subsection{Total anthocyanin content (TAC)}

The total monomeric anthocyanin content was determined using the $\mathrm{pH}$-differential method as described by Giusti and Wrolstad [27] with some modifications. This method benefits from the structural transformations revealed by the anthocyanin chromophore as a function of $\mathrm{pH}$. The absorption of the sample is measured at $\mathrm{pH} 1$ (anthocyanins as colored oxonium salts) as well as at $\mathrm{pH} 4.5$ (anthocyanins as colorless hemiketals). As anthocyanin degradation products do not exhibit reversible behavior with $\mathrm{pH}$, they are excluded from the absorbance calculation [28]. Haskap extracts were spectrophotometrically scanned to investigate their absorbance spectra. The wavelength of maximum absorption $(\lambda \max )$ was found to be $520 \mathrm{~nm}$. Spectrophotometric measurements were therefore carried out at $520 \mathrm{~nm}$ and $700 \mathrm{~nm}$. The calculation of monomeric anthocyanins is based on the molecular weight (MW) and the molar extinction coefficient $(\varepsilon)$ of the main anthocyanin in the sample: cyanidin-3-glucoside (cyd-3-glu) (extinction coefficient of $26,900 \mathrm{M}^{-1} \mathrm{~cm}^{-1}$ and molecular weight of $449.38 \mathrm{~g} / \mathrm{mol}$ ). A $1 \mathrm{~cm}$ path length quartz cuvette was used and the measurements were carried out at room temperature. Absorbance was read against distilled water as a blank and the TAC was calculated according to Equation 1. 


$$
T A C(m g / L)=(A \times M W \times D F \times 1000) /(\varepsilon \times 1)
$$

Where:

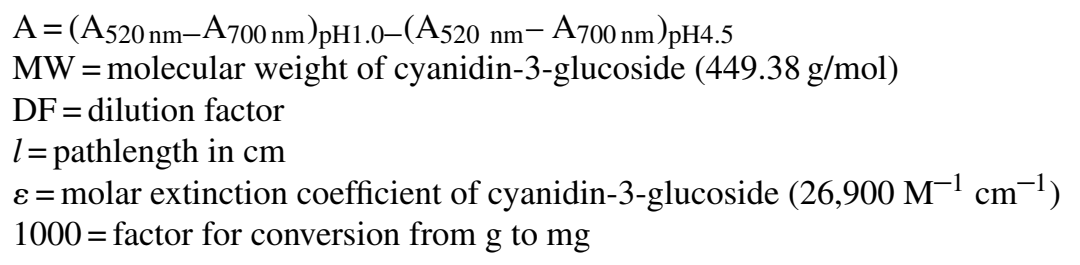

\subsection{Free radical scavenging activity}

The free radical scavenging activities of Haskap extracts were assessed using the 1,1-diphenyl-2-picrylhydrazyl (DPPH) method according to Mitraa et al. [29] with some modifications. Extract $(0.1 \mathrm{~mL})$ was dissolved in $2.9 \mathrm{~mL}$ of $0.10 \mathrm{mM}$ DPPH solution and the differences before $(\mathrm{t}=0 \mathrm{~min})$ and after $(\mathrm{t}=10 \mathrm{~min})$ sample addition were read at $516 \mathrm{~nm}$ using the Genesys $10 \mathrm{~S}$ UV/Visible spectrophotometer (Thermo Scientific, Marietta, OH, USA). The antioxidant scavenging effect was calculated from Equation 2:

$$
\text { Scavenging effect }(\%)=\left[\frac{(A b-A s)}{A b}\right] \times 100
$$

Where: $A_{b}$ is absorbance of the control (DPPH solution without test sample). $A_{s}$ is the absorbance of the test sample (DPPH solution plus Haskap extract).

\subsection{Statistical analysis}

Data were analyzed using a one factor analysis of variance (ANOVA). Tukey-Kramer mean separation tests were carried out for multiple comparisons with SigmaStat software (version 3.5) (Systat Software, Inc., San Jose, CA, USA) where the significance was accepted at $p \leq 0.05$.

\section{Results and discussion}

\subsection{Total phenolic content (TPC)/Total reducing capacity (TRC), total anthocyanin content (TAC) and free radical scavenging activity of fresh Haskap berries}

The TPC/TRC, TAC, and DPPH scavenging activity of fresh Haskap berries are shown in Table 1. Despite the wide-use of the Folin Ciocalteu assay, its specificity to measure the total phenolic content (TPC) has been recently questioned because of the possible interference of other reducing substances such as ascorbic acid (vitamin C) and reducing sugars which can relatively overestimate the TPC [30, 31]. Therefore, this assay has been used in this study as an indication of the total reducing capacity (TRC) of the extracts which is mainly attributed to the phenolic compounds with possible contribution caused by ascorbic acid. The three investigated varieties; Tundra (T), Blue Berry $(B B)$, and Indigo Gem (IG) showed TPC values of 8.09 $\pm 0.03,6.17 \pm 0.00$ and $8.42 \pm 0.02 \mathrm{mg}$ GAE/g FW, respectively. These values come in the range reported for Haskap berries and agree with other investigators $[8,10$, 32]. The variation found in the TPC could be attributed to varietal and maturation effects.

The TAC values (Table 1) were $6.13 \pm 0.06,4.49 \pm 0.14$ and $6.97 \pm 0.16 \mathrm{mg}$ cyd-3-glu equivalents/g FW in T, BB and IG varieties, respectively. The TAC of other Haskap berry varieties was found to be up to $13.00 \mathrm{mg}$ cyd-3-glu equivalents/g FW [8, 9], and 8.58-19.18 mg cyd-3-glu equivalents/g FW [33, 34] which is higher than the values found in this study. The difference in TAC among studies might be attributed to varietal, environmental as well as extraction conditions.

The DPPH scavenging activities (Table 1) of the three varieties were $88.42 \pm 0.77,78.70 \pm 0.33$ and $89.55 \pm 0.44 \%$, respectively. The lowest value was recorded for the BB which contained the lowest TPC and TAC. It was reported 
Table 1

Total phenolic content (TPC)/total reducing capacity (TRC), total anthocyanin content (TAC), and antioxidant activity of fresh Haskap berries*

\begin{tabular}{lccc}
\hline & Tundra (T) & Berry Blue (BB) & Indigo Gem (IG) \\
\hline TPC/TRC (mg GAE/g FW) & $8.09 \pm 0.03^{\mathrm{a}}$ & $6.17 \pm 0.00^{\mathrm{b}}$ & $8.42 \pm 0.02^{\mathrm{a}}$ \\
TAC (mg Cyd-3-glu/g FW) & $6.13 \pm 0.06^{\mathrm{a}}$ & $4.49 \pm 0.14^{\mathrm{b}}$ & \\
DPPH scavenging activity (\%) & $88.42 \pm 0.77^{\mathrm{a}}$ & $78.70 \pm 0.33^{\mathrm{b}}$ & \\
\hline
\end{tabular}

${ }^{*} \mathrm{GAE}=$ gallic acid equivalents, FW = fresh weight, Cyd-3-glu = cyanidin-3-glucoside equivalents, DPPH = 2,2-diphenyl-1-picrylhydrazyl. Values are means of four replicates \pm standard deviation Values in the same row followed by the same superscript letter are not significantly different according to the Tukey-Kramer test $(p \leq 0.05)$.

Table 2

Degradation (\%) in total phenolic content (TPC)/total reducing capacity (TRC), total anthocyanin content (TAC), and antioxidant potential (DPPH radical scavenging activity) of Haskap berries upon frozen storage for six months at different conditions

\begin{tabular}{|c|c|c|c|c|c|c|c|c|c|}
\hline & \multicolumn{3}{|c|}{ Tundra (T) } & \multicolumn{3}{|c|}{ Berry Blue (BB) } & \multicolumn{3}{|c|}{ Indigo Gem (IG) } \\
\hline & $\mathrm{T} 1$ & $\mathrm{~T} 2$ & $\mathrm{~T} 3$ & $\mathrm{~T} 1$ & $\mathrm{~T} 2$ & $\mathrm{~T} 3$ & $\mathrm{~T} 1$ & $\mathrm{~T} 2$ & $\mathrm{~T} 3$ \\
\hline \multicolumn{10}{|l|}{ TPC/TRC } \\
\hline Month 1 & 15.20 & 13.72 & 14.34 & 28.04 & 24.80 & 25.93 & 25.53 & 23.16 & 24.35 \\
\hline Month 2 & 23.36 & 21.26 & 22.87 & 31.93 & 29.17 & 30.96 & 32.42 & 28.62 & 31.47 \\
\hline Month 3 & 29.30 & 27.69 & 29.05 & 37.44 & 34.85 & 36.47 & 38.12 & 34.44 & 36.94 \\
\hline Month 4 & 33.62 & 32.39 & 33.25 & 41.98 & 40.03 & 40.84 & 42.16 & 38.48 & 40.97 \\
\hline Month 5 & 35.85 & 34.61 & 35.48 & 45.22 & 43.11 & 44.08 & 44.42 & 40.74 & 43.11 \\
\hline Month 6 & 37.08 & 35.85 & 36.84 & 47.16 & 44.89 & 46.52 & 45.72 & 41.81 & 44.54 \\
\hline \multicolumn{10}{|l|}{ TAC } \\
\hline Month 1 & 28.38 & 16.48 & 19.25 & 40.76 & 33.41 & 38.53 & 32.42 & 25.11 & 30.42 \\
\hline Month 2 & 31.16 & 22.68 & 28.55 & 47.44 & 42.32 & 45.43 & 35.44 & 34.15 & 34.15 \\
\hline Month 3 & 33.61 & 27.08 & 31.48 & 53.23 & 48.33 & 51.45 & 41.32 & 39.02 & 39.74 \\
\hline Month 4 & 37.19 & 30.67 & 34.58 & 56.12 & 51.45 & 53.67 & 43.90 & 41.61 & 42.47 \\
\hline Month 5 & 38.01 & 31.48 & 35.40 & 57.24 & 52.56 & 54.79 & 44.76 & 42.47 & 43.33 \\
\hline Month 6 & 39.31 & 32.79 & 36.87 & 59.24 & 54.34 & 56.57 & 46.34 & 43.62 & 45.19 \\
\hline \multicolumn{10}{|c|}{ DPPH radical scavenging activity } \\
\hline Month 1 & 14.83 & 13.14 & 14.78 & 13.28 & 11.61 & 11.78 & 12.07 & 11.61 & 11.97 \\
\hline Month 2 & 18.06 & 17.26 & 17.79 & 18.74 & 18.39 & 18.51 & 16.07 & 15.57 & 15.72 \\
\hline Month 3 & 21.23 & 20.43 & 21.13 & 23.57 & 23.27 & 23.51 & 20.06 & 19.85 & 19.91 \\
\hline Month 4 & 24.39 & 23.59 & 24.38 & 27.31 & 26.26 & 26.96 & 23.32 & 23.22 & 23.27 \\
\hline Month 5 & 26.09 & 25.29 & 26.08 & 29.47 & 28.42 & 29.12 & 25.33 & 25.23 & 25.28 \\
\hline Month 6 & 27.26 & 26.44 & 27.22 & 30.86 & 29.82 & 30.65 & 26.78 & 26.34 & 26.45 \\
\hline
\end{tabular}

$\mathrm{DPPH}=2$,2-diphenyl-1-picrylhydrazyl; $\mathrm{T} 1$ : frozen storage at $-18^{\circ} \mathrm{C} ; \mathrm{T} 2$ : steam blanching followed by frozen storage at $-18^{\circ} \mathrm{C} ; \mathrm{T} 3$ : frozen storage at $-32^{\circ} \mathrm{C}$.

that Haskap berry extracts could scavenge $85 \%$ of DPPH as compared to 43,74 , and $51 \%$ for tomato, sea buckthorn, and standard ascorbic acid, respectively [6]. These results further agree with others reported by Rupasinghe et al. [10] and Zhao et al. [35].

\subsection{Effect of frozen storage on the phenolic profile and antioxidant potential of Haskap berries}

The effects of frozen storage at different conditions on the TPC/TRC, TAC, and antioxidant potential (DPPH radical scavenging activity) of Haskap berries are illustrated in Figs. 1, 2 and 3, respectively. The reduction (\%) caused by different treatments is shown in Table 2 . 

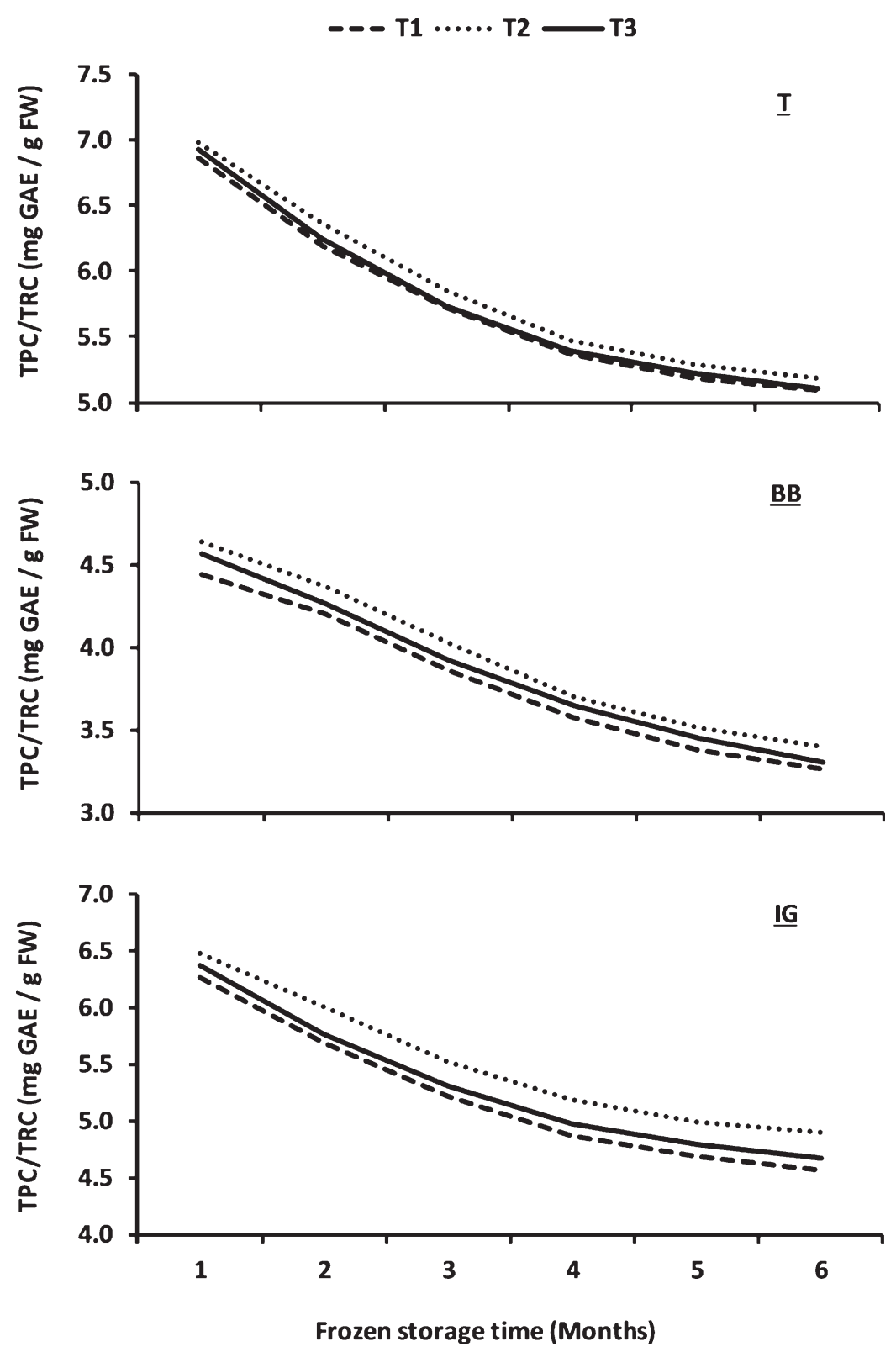

Fig. 1. Effect of frozen storage conditions on the total phenolic content (TPC)/total reducing capacity (TRC) of Haskap berries. T1: frozen storage at $-18^{\circ} \mathrm{C} ; \mathrm{T} 2$ : steam blanching followed by frozen storage at $-18^{\circ} \mathrm{C}$; T3: frozen storage at $-32^{\circ} \mathrm{C}$; T: Tundra; BB: Berry Blue; IG: Indigo Gem.

\subsubsection{Effect of standard frozen storage, $T 1\left(-18^{\circ} \mathrm{C}\right)$}

The changes in the TPC/TRC are shown in Fig. 1 for all varieties. The standard frozen storage (T1) for one month reduced the TPC/TRC by $15.20 \pm 0.18,28.04 \pm 0.24$ and $25.53 \pm 0.21 \%$ in the three varieties $(\mathrm{T}, \mathrm{BB}$, and IG), respectively. The difference found among varieties may be attributed to the differences in fruit maturation, physical structure and softness. The second month of storage could further reduce the TPC/TRC only by $8.16 \pm 0.03$, $3.89 \pm 0.01$ and $6.89 \pm 0.02 \%$ in the three varieties, respectively. The reduction rate started to decrease over the storage period and each consequent month was causing less degradation than the preceding one. The reductions caused by the sixth month were $1.23 \pm 0.00,1.94 \pm 0.01$ and $1.30 \pm 0.00 \%$, respectively. The corresponding total 

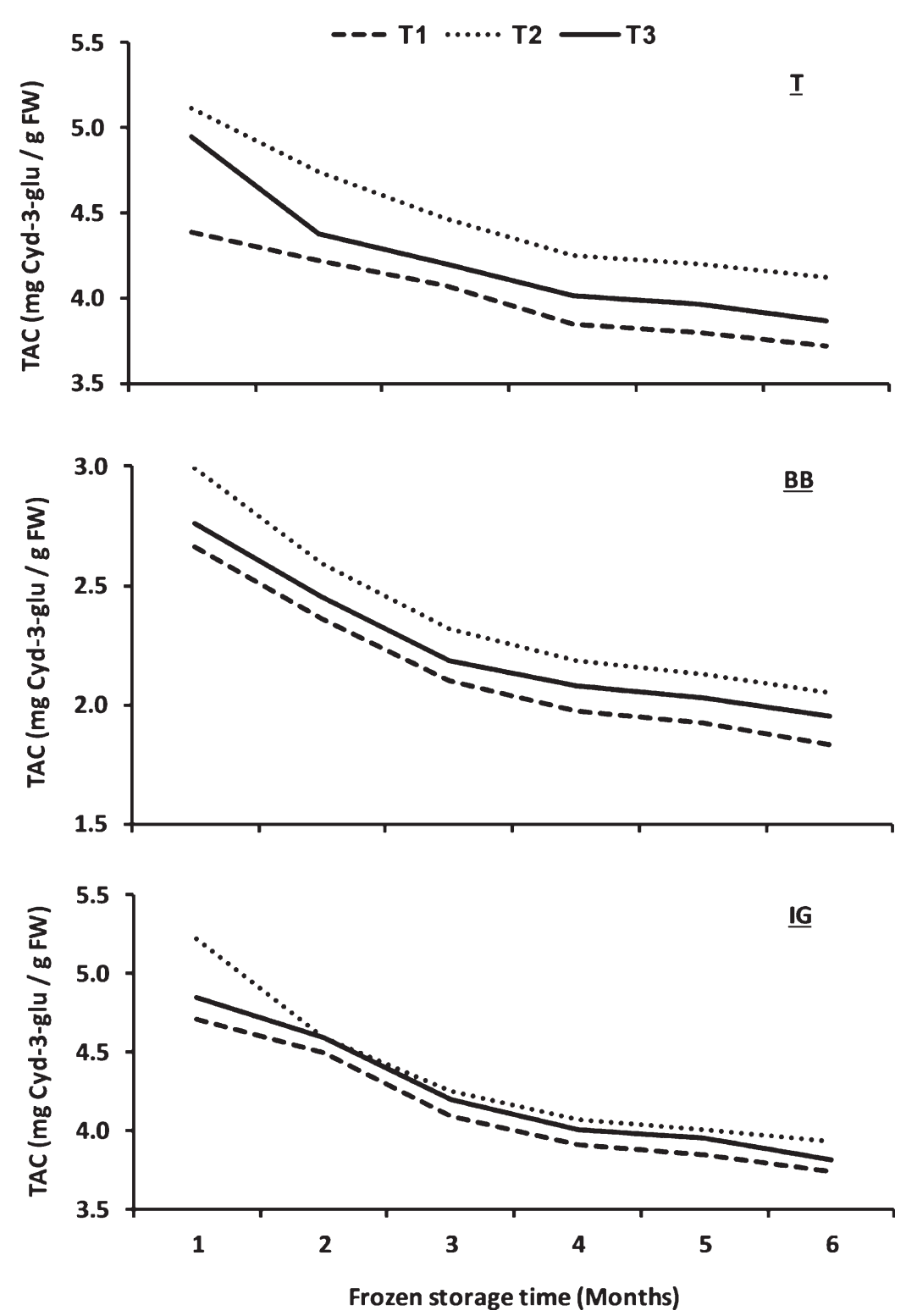

Fig. 2. Effect of frozen storage conditions on the total anthocyanin content (TAC) of Haskap berries. $\mathrm{T} 1$ : frozen storage at $-18^{\circ} \mathrm{C}$; $\mathrm{T} 2$ : steam blanching followed by frozen storage at $-18^{\circ} \mathrm{C}$; T3: frozen storage at $-32^{\circ} \mathrm{C}$; T: Tundra; BB: Berry Blue; IG: Indigo Gem.

reductions after the sixth month (Table 2) were $37.08 \pm 0.21,47.16 \pm 0.24$ and $45.72 \pm 0.22 \%$, respectively. It was concluded that the major reductions occurred during the first three months after which the reduction rates were decreasing gradually. It is anticipated from this decrease in the reduction rates with storage time that the values of TPC may reach a plateau during the seventh or eighth month of storage. The reduction in the total anthocyanin content (TAC) (Fig. 2) followed the same trend seen for the TPC (Fig. 1). After six months, the highest reduction was found in the BB $(59.24 \pm 0.26 \%)$ followed by IG $(46.34 \pm 0.23 \%)$ (Table 2$)$. The increment rate decreased from month to month within the storage period where the last month brought reductions of only $1.30 \pm 0.00,2.00 \pm 0.01$ and $1.58 \pm 0.01 \%$ in the three varieties, respectively.

The changes in the antioxidant potential (DPPH scavenging activity) (Fig. 3) followed similar trend and reflected the changes in both TPC and TAC. Standard frozen storage for six months resulted in $27.26 \pm 0.11,30.86 \pm 0.14$ and 
$26.78 \pm 0.10 \%$ decreases in the radical scavenging activity in T, BB, and IG, respectively (Table 2). This reduction is attributed to the decreases in polyphenols and anthocyanins that are responsible for the antioxidant effect potential of haskap berries. Patthamakanokporn et al. [36] evaluated the changes in the antioxidant activity and total phenolic compounds of guava (Psidium guajava), makiang (Cleistocalyx nervosum) and maluod (Elaeagnus iatifolia) fruits during storage at $-20^{\circ} \mathrm{C}$ for three months. After two weeks of storage, the antioxidant activity decreased significantly by $23 \%$ and $62 \%$ in guava and maluod, respectively. They found a continuous decrease in the total phenolic compounds in guava fruits throughout the 3-months storage period (69\% retention) whereas constant levels were found in other fruits. Our results agree with those reported by Mirsaeedghazi et al. [20] who found that frozen storage of pomegranate juice at $-25^{\circ} \mathrm{C}$ for 20 days decreased the TAC, TPC, and DPPH radical scavenging activity by $11 \%, 29 \%$, and $50 \%$, respectively. Furthermore, Chaovanalikit \& Wrolstad [21] found that more than $75 \%$ of anthocyanins in frozen cherries were destroyed after six months of storage at $-23^{\circ} \mathrm{C}$. These results further agree with those reported for strawberries [18, 19, 22], sweet cherries and sour cherries [22].

The ellagic acid, total phenolic, and vitamin C contents in raspberry fruits were quantified by HPLC in fresh, just frozen, and frozen stored $\left(-20^{\circ} \mathrm{C}\right.$ for one year) [24]. The researchers concluded that the freezing process slightly affected the values of ellagic acid, total phenols, and vitamin $\mathrm{C}$ contents. After 12 months, significant decreases in ellagic acid (14-21\%) and vitamin C (33-55\%) were detected. The whole freezing process produced 4-26\% decrease of the antiradical efficiency. The degradation effect was attributed to the frozen storage and the thawing process and not to the freezing itself. The results of this study, however, deviate from those reported on the frozen storage of blueberries [23] and raspberries [17, 24] where no significant decreases in anthocyanin level, TPC and antioxidant activity were found.

\subsubsection{Effect of steam blanching as a pre-freezing treatment, $T 2$ (Blanched and $\left.-18^{\circ} \mathrm{C}\right)$}

The effect of steam blanching as a pre-freezing treatment on the TPC/TRC, TAC and antioxidant activity of Haskap berries is shown in Figs. 1, 2 and 3, respectively. Compared to the standard freezing (T1), steam-blanched fruits (T2) showed higher retention of phenolic compounds and better antioxidant activity throughout the frozen storage period (up to six months). This effect was found in the three investigated varieties. Steam blanching is known to cause the minimum losses in phytochemicals and antioxidant capacity [37, 38]. Furthermore, it requires less time than conventional blanching because the heat transfer coefficient of condensing steam is greater than that of hot water and it is proven to be comparatively more economical as it saves energy [39]. In this research, steam blanching could preserve the phenolic compounds during the frozen storage as compared to the un-blanched samples, although the improvement was not significant in some conditions. The reductions in the TPC/TRC after six months (Table 2) were $35.85 \pm 0.20,44.49 \pm 0.22$ and $41.81 \pm 0.21 \%$ in T, BB and IG, respectively as compared to $37.08 \pm 0.21$, $47.16 \pm 0.24$ and $45.72 \pm 0.22 \%$ in the standard freezing (without blanching). The reductions in TAC $(32.79 \pm 0.18$, $54.34 \pm 0.23$ and $43.62 \pm 0.21 \%)$ were significantly lower than those caused by the standard freezing $(39.31 \pm 0.20$, $59.24 \pm 0.26$ and $46.34 \pm 0.23 \%$ ). This effect may be attributed to the inhibition of the polyphenol oxidase (PPO) and other oxidative enzymes that catalyze oxidative reactions causing a significant decrease of phenolic compounds and anthocyanins [40-42].

Ahmed and Ali [43] compared the effect of water blanching and steam blanching on the nutrients, phytochemicals, antioxidant activity (measured by DPPH assay), and phenolic profiles of white cauliflower. They found that steam blanching for $3 \mathrm{~min}$ presented the lowest reduction in phenolic content. Methanolic extract of fresh cauliflower had the highest antioxidant activity $(68.91 \%)$ followed by the extract of the steam-blanched sample $(61.83 \%)$, while the lowest value was that of water-blanched sample $\left(100^{\circ} \mathrm{C}\right.$ for 3 minutes). We found that blanching could retain the DPPH radical scavenging activities of different Haskap varieties as compared to the standard freezing (Table 2). Blanching was found to be a promising pre-treatment as it could contribute to the retention of phenolics in all cases as compared to the standard freezing. The insignificant effects in some conditions may be due to the blanching time $(20 \mathrm{~s})$, which might not have been sufficient to totally inactivate the enzymes as the heat may not have penetrated to the center of the fruits. Blanching is usually carried out at $75-95^{\circ} \mathrm{C}$ for 1 to 10 minutes, depending on the size of individual product pieces [44]. The blanching conditions could be further optimized in future work for a higher preservative effect. 

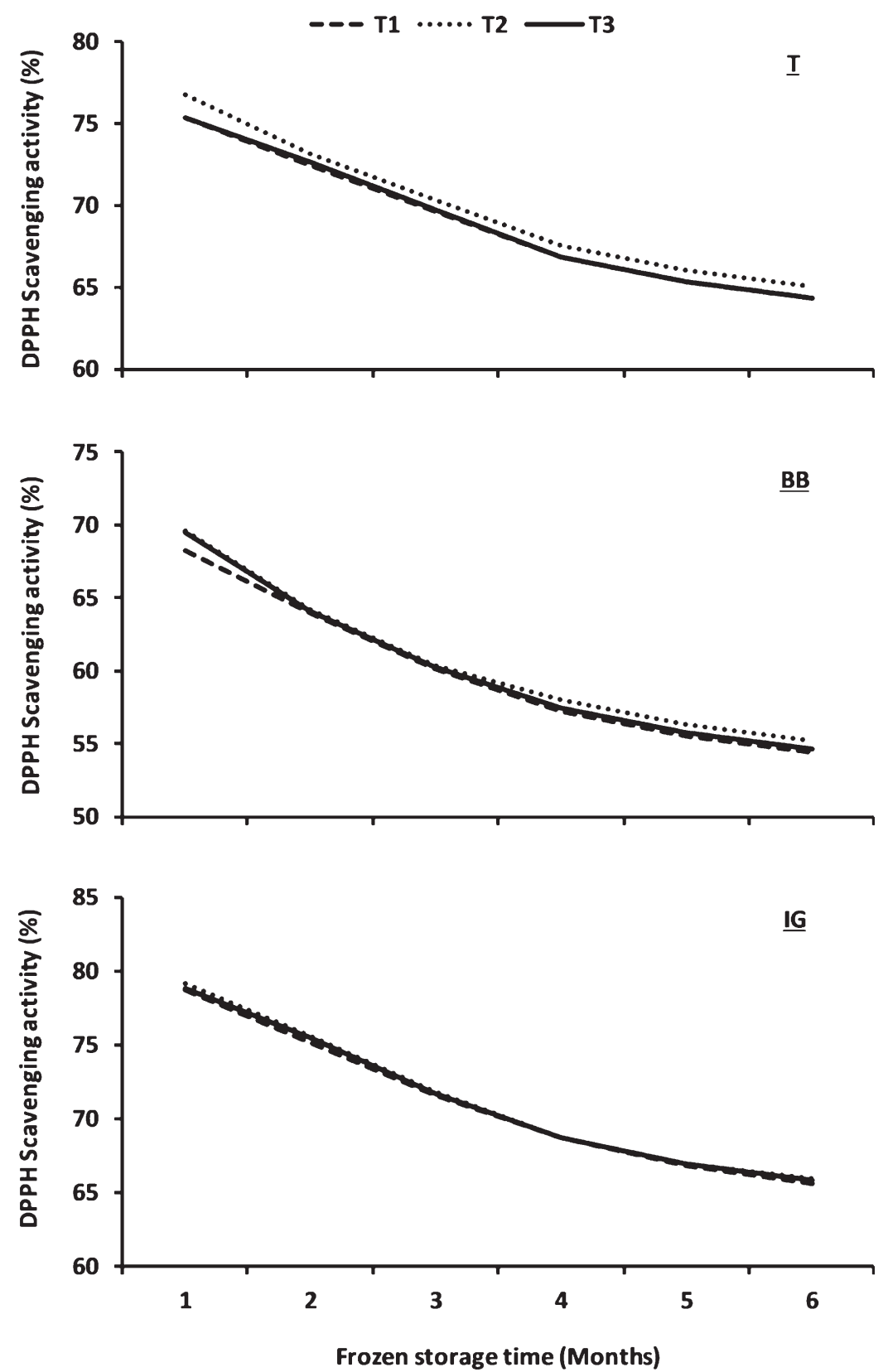

Fig. 3. Effect of frozen storage conditions on the DPPH radical scavenging activity of Haskap berries. T1: frozen storage at $-18^{\circ} \mathrm{C}$; $\mathrm{T} 2$ : steam blanching followed by frozen storage at $-18^{\circ} \mathrm{C}$; T3: frozen storage at $-32^{\circ} \mathrm{C}$; T: Tundra; BB: Berry Blue; IG: Indigo Gem.

\subsubsection{Effect of lower temperature storage, $T 3\left(-32^{\circ} \mathrm{C}\right)$}

The effect of lower temperature frozen storage $\left(-32^{\circ} \mathrm{C}\right)$ for six months on the retention of phenolic compounds and antioxidant potential was investigated and compared to the standard frozen storage at $-18^{\circ} \mathrm{C}(\mathrm{T} 1)$. The results (Figs. 1 to 3) showed that TPC/TRC decreased from $8.09 \pm 0.03,6.17 \pm 0.00$ and $8.42 \pm 0.02$ to $5.11 \pm 0.02(36.84 \pm 0.19 \%$ reduction), $3.30 \pm 0.01$ (46.52 $\pm 0.22 \%$ reduction) and $4.67 \pm 0.01 \mathrm{mg} \mathrm{GAE} / \mathrm{g} \mathrm{FW}(44.54 \pm 0.20 \%$ reduction) in the three varieties T, BB and IG, respectively. These reductions were slightly lower but not significantly different from those found in the standard frozen storage at $-18^{\circ} \mathrm{C}(37.08 \pm 0.21,47.16 \pm 0.24$ and $45.72 \pm 0.22 \%$, respectively). 
The reductions in TAC in the three varieties were $36.87 \pm 0.20,56.57 \pm 0.24$ and $45.19 \pm 0.22 \%$, respectively which did not significantly differ from those caused by the standard frozen storage. Likewise, storage at $-32^{\circ} \mathrm{C}$ did not significantly reduce the DPPH radical scavenging activity $(27.22 \pm 0.10,30.65 \pm 0.14$ and $26.45 \pm 0.10 \%)$ compared to $-18^{\circ} \mathrm{C}(27.26 \pm 0.11,30.86 \pm 0.14$ and $26.78 \pm 0.10 \%$ in the three varieties, respectively). These results indicate that the reducing effect is attributed to the freezing storage itself rather than to the freezing temperature. As long as the berries were stored frozen, the difference in the frozen storage temperature did not impart a significant effect. These results agree with those reported by Polinati et al. [25] who evaluated the influence of low temperature storage $\left(-18^{\circ} \mathrm{C}\right.$ and $\left.-70^{\circ} \mathrm{C}\right)$ for 10 days on the antioxidant capacity of apple and orange extracts. The authors found that frozen storage at $-18^{\circ} \mathrm{C}$ did not result in different antioxidant capacity when compared to frozen storage at $-70^{\circ} \mathrm{C}$.

In all treatments, the highest reductions in TPC/TRC, TAC and DPPH radical scavenging activity were found in the BB variety followed by IG. This may be attributed to the highest degree of ripeness and softness in BB fruits compared to those of the other two varieties. For all measured parameters measured, the first three months contributed to most of the degradation observed. Afterwards, each consequent month resulted in a smaller amount of degradation.

\section{Conclusion}

The standard frozen storage of Haskap berries at $-18^{\circ} \mathrm{C}$ for six months (T1) significantly reduced TPC/TRC, TAC and DPPH radical scavenging activity. The major reductions occurred in the first three months, after which the reduction rates decreased gradually over the storage period and each month caused less effect than the previous month. The highest reductions were found in the Berry Blue variety followed by Indigo Gem and Tundra. Steam blanching of berries prior to freezing (T2) improved the retention of phenolics, anthocyanins and antioxidant activity. Lower temperature frozen storage at $-32^{\circ} \mathrm{C}$ (T3) did not significantly improve the phenolics and anthocyanin retention and antioxidant activity of Haskap berries as compared to the standard procedure (T1). Both T1 and T3 differed significantly from $\mathrm{T} 2$ but not between each other. Further research is needed to improve the steam blanching conditions in order to optimize the preservative effect. The effect of different thawing conditions on the retention of phenolics, anthocyanins and antioxidant properties is currently under investigation.

\section{Acknowledgments}

This work was funded by the Natural Sciences and Engineering Research Council of Canada (NSERC). LaHave Natural Farms, Blockhouse, Nova Scotia, Canada is sincerely acknowledged for providing the Haskap berries used in this study. G.B. Celli is grateful to the National Council for Research and Development (CNPq-Brazil) for financial support.

\section{References}

[1] Paredes-Lopez O, Cervantes-Ceja ML, Vigna-Perez M, Hernandez-Perez T. Berries: Improving human health and healthy aging, and promoting quality life - a review. Plant Food Hum Nutr. 2010;65:299.

[2] Seeram NP. Emerging research supporting the positive effects of berries on human health and disease prevention. J Agric Food Chem. 2012;60:5685.

[3] Jurikova T, Rop O, Mlcek J, Sochor J, Balla S, Szekeres L, et al. Phenolic profile of edible honeysuckle berries (Genus Lonicera) and their biological effects - a review. Molecules. 2012;17:61.

[4] Bors B, Thomson J, Sawchuk E, Reimer P, Sawatzky R, Sander T. Haskap breeding and production—final report. Regina, Canada: Saskatchewan Agriculture: Regina 2012.

[5] Rop O, Řezníček V, Mlček J, Juríková T, Balík J, Sochor J. Antioxidant and radical oxygen species scavenging activities of 12 cultivars of blue honeysuckle fruit. Hortic Sci. 2011;38:63.

[6] Raudsepp P, Anton D, Roasto M, Meremäe K, Pedastsaar P, Mäesaar M. The antioxidative and antimicrobial properties of the blue honeysuckle (Lonicera caerulea L.), Siberian rhubarb (Rheum rhaponticum L.) and some other plants, compared to ascorbic acid and sodium nitrite. Food Control. 2013; 31:129.

[7] Celli GB, Ghanem A, Brooks MS. Haskap berries (Lonicera caerulea L.) - a critical review of antioxidant capacity and health-related studies for potential value-added products. Food Bioprocess Technol. 2014;7:1541. 
[8] Bakowska A, Marianchuk M, Kolodziejczyk P. Survey of bioactive components in Western Canadian berries. Can J Physiol Pharmacol. 2007;85:1139.

[9] Fan Z, Wang Z, Liu J. Cold-field fruit extracts exert different antioxidant and antiproliferative activities in vitro. Food Chem. 2011;129:402.

[10] Rupasinghe HPV, Yu LJ, Bhullar KS, Bors B. Haskap (Lonicera caerulea): A new berry crop with high antioxidant capacity. Can J Plant Sci. 2012;92:1311.

[11] Zhao Y. Freezing process of berries. In: Zhao Y, editor. Berry fruit: Value-added products for health promotion. FL, USA: Boca Raton, CRC Press; 2007. pp. 292.

[12] Rickman C, Barrett DM, Bruhn CM. Nutritional comparison of fresh, frozen and canned fruits and vegetables. Part 1. Vitamins C and B and phenolic compounds. J Sci Food Agric. 2007;87:930.

[13] Puupponen-Pimia R, Häkkinen ST, Aarni M, Suortti T, Lamp A-M, Eurola M, et al. Blanching and long-term freezing affect various bioactive compounds of vegetables in different ways. J Sci Food Agric. 2003;83:1389.

[14] Leong SY, Oey I. Effects of processing on anthocyanins, carotenoids and vitamin C in summer fruits and vegetables. Food Chem. 2012;133:1577.

[15] De Ancos B, Ibanez E, Reglero G, Cano MP. Frozen storage effects on anthocyanins and volatile compounds of raspberry fruit. J Agric Food Chem. 2000b; $48: 873$

[16] Häkkinen SH, Kärenlampi SO, Mykkänen HM, Törrönen AR. Influence of domestic processing and storage on flavonol contents in berries. J Agric Food Chem. 2000;48:2960.

[17] Mullen W, Stewart AJ, Lean MEJ, Gardner P, Duthie GG, Crozier A. Effect of Freezing and Storage on the Phenolics, Ellagitannins, Flavonoids, and Antioxidant Capacity of Red Raspberries. J Agric Food Chem. 2002;50:5197.

[18] Hartmann A, Patz CD, Andlauer W, Dietrich H, Ludwig M. Influence of processing on quality parameters of strawberries. J Agric Food Chem. 2008;56:9484

[19] Oszmiański J, Wojdylo A, Kolniak J. Effect of L-ascorbic acid, sugar, pectin and freeze-thaw treatment on polyphenol content of frozen strawberries. Food Sci Technol. 2009;42:581

[20] Mirsaeedghazi H, Emam-Djomeh Z, Ahmadkhaniha R. The effect of frozen storage on the anthocyanins and polyphenolic components of pomegranate juice. J Food Sci Technol. 2014;51:382.

[21] Chaovanalikit A, Wrolstad RE. Total anthocyanins and total phenolics of fresh and processed cherries and their antioxidant properties. J Food Sci. 2004;69:FCT67.

[22] Poiana MA, Moigradean D, Alexa E. Influence of home scale freezing and storage on antioxidant properties and color quality of different garden fruits. Bulg J Agric Sci. 2010;16:163.

[23] Lohachoompol V, Srzednicki G, Craske J. The Change of Total Anthocyanins in Blueberries and Their Antioxidant Effect After Drying and Freezing. J Biomed Biotechnol. 2004;5:248

[24] De Ancos B, Gonzalez EM, Cano MP. Ellagic acid, vitamin C, and total phenolic contents and radical scavenging capacity affected by freezing and frozen storage in raspberry fruit. J Agric Food Chem. 2000a;48:4565.

[25] Polinati RM, Faller ALK, Fialho E. The effect of freezing at $-18^{\circ} \mathrm{C}$ and $-70^{\circ} \mathrm{C}$ with and without ascorbic acid on the stability of antioxidant in extracts of apple and orange fruits. Int J Food Sci Technol. 2010;45:1814.

[26] Singleton VL, Orthofer R, Lamuela-Raventós RM. Analysis of total phenols and other oxidation substrates and antioxidants by means of Folin-Ciocalteu reagent. Methods Enzymol. 1999;299:152.

[27] Giusti M, Wrolstad R. Characterization and measurement of anthocyanins by UV-visible spectroscopy. Curr Protoc Food Anal Chem. 2001;F1.2.1.

[28] Fuleki T, Francis FJ. Quantitative methods for anthocyanins. II. Determination of total anthocyanin and degradation index for cranberry juice. J Food Sci. 1968;33:78

[29] Mitraa P, Medaa V, Greenb R. Effect of drying techniques on the retention of antioxidant activities of Saskatoon berries. Int J Food Stud. $2013 ; 2: 224$.

[30] Huang D, Ou B, Prior RL. The chemistry behind antioxidant capacity assays. J Agric Food Chem. 2005;53:1841.

[31] Everette JD, Bryant QM, Green AM, Abbey YA, Wangila GW, Walker RB. Thorough study of reactivity of various compound classes toward the folin-Ciocalteu reagent. J Agric Food Chem. 2010;58:8139.

[32] Thompson M, Chaovanalikit A. Preliminary observations on adaptation and nutraceutical values of blue honeysuckle (Lonicera caerulea) in Oregon, USA. Acta Hortic. 2003;626:65.

[33] Turianica I, Jurikova T, Paulovicsova B, Baloghova M, Matuskovic J. Non-traditional fruit species as a important source of natural colouring matters. Vistnik stomatologii. 2008;16:41.

[34] Paulovicsova B, Turianica I, Jurikova T, Baloghova M, Matuskovic J. Antioxidant properties of selected less common fruit species. Lucrari Stiifice Zootehnie si Biotechnologii. 2009;42:608.

[35] Zhao H, Wang Z, Cheng C, Yao L, Wang L, Lu W. In-vitro free radical scavenging activities of anthocyanins from three berries. J Med Plant Res. 2011;5:7036.

[36] Patthamakanokporn O, Puwastien P, Nitithamyong A, Sirichakwal PP. Changes of antioxidant activity and total phenolic compounds during storage of selected fruits. J Food Compos Anal. 2008;21:241. 
[37] Podsedek A, Sosnowska D, Redzynia M, Koziolkiewicz M. Effect of domestic cooking on the red cabbage hydrophyllic antioxidants. Int J Food Sci Technol. 2008;43:1770.

[38] Faller A, Fialho E. The antioxidant capacity and polyphenol content of organic and conventional retail vegetables after domestic cooking. Food Res Int. 2009;42:210.

[39] De Corcuera JIR, Cavalieri RP, Powers JR. Blanching of Foods. In: Heldman D, editor. Encyclopedia of Agricultural, Food, and Biological Engineering. New York, USA: Marcel Dekker Inc; 2004. pp. 1.

[40] De Leonardis A, Macciola V. Polyphenol oxidase from eggplant reduces the content of phenols and oxidative stability of olive oil. Eur J Lipid Sci Technol. 2011;113:1124-31.

[41] Kader F, Nicolas JP, Metche M. Degradation of pelargonidin 3-glucoside in the presence of chlorogenic acid and blueberry polyphenol oxidase. J Sci Food Agric. 1999;79:517-22.

[42] Makris DP, Rossiter JT. Comparison of quercetin and a non-orthohydroxy flavonol as antioxidants by competing in vitro oxidation reactions. J Agric Food Chem. 2001;49:3370-77.

[43] Ahmed FA, Ali RFM. Bioactive compounds and antioxidant activity of fresh and processed white cauliflower. Biomed Res Int. 2013; Article ID 367813.

[44] De Ancos B, Sanchez-Moreno C, De Pascual-Teresa S, Cano MP. Fruit freezing principles. In: Hui YH, editor. Handbook of fruits and fruit processing. Oxford, UK: Blackwell publishing; 2006. pp. 59. 